\title{
AGAMA DAN PEMBANGUNAN EKONOMI REGIONAL DI BANTEN TAHUN 2000-2016
}

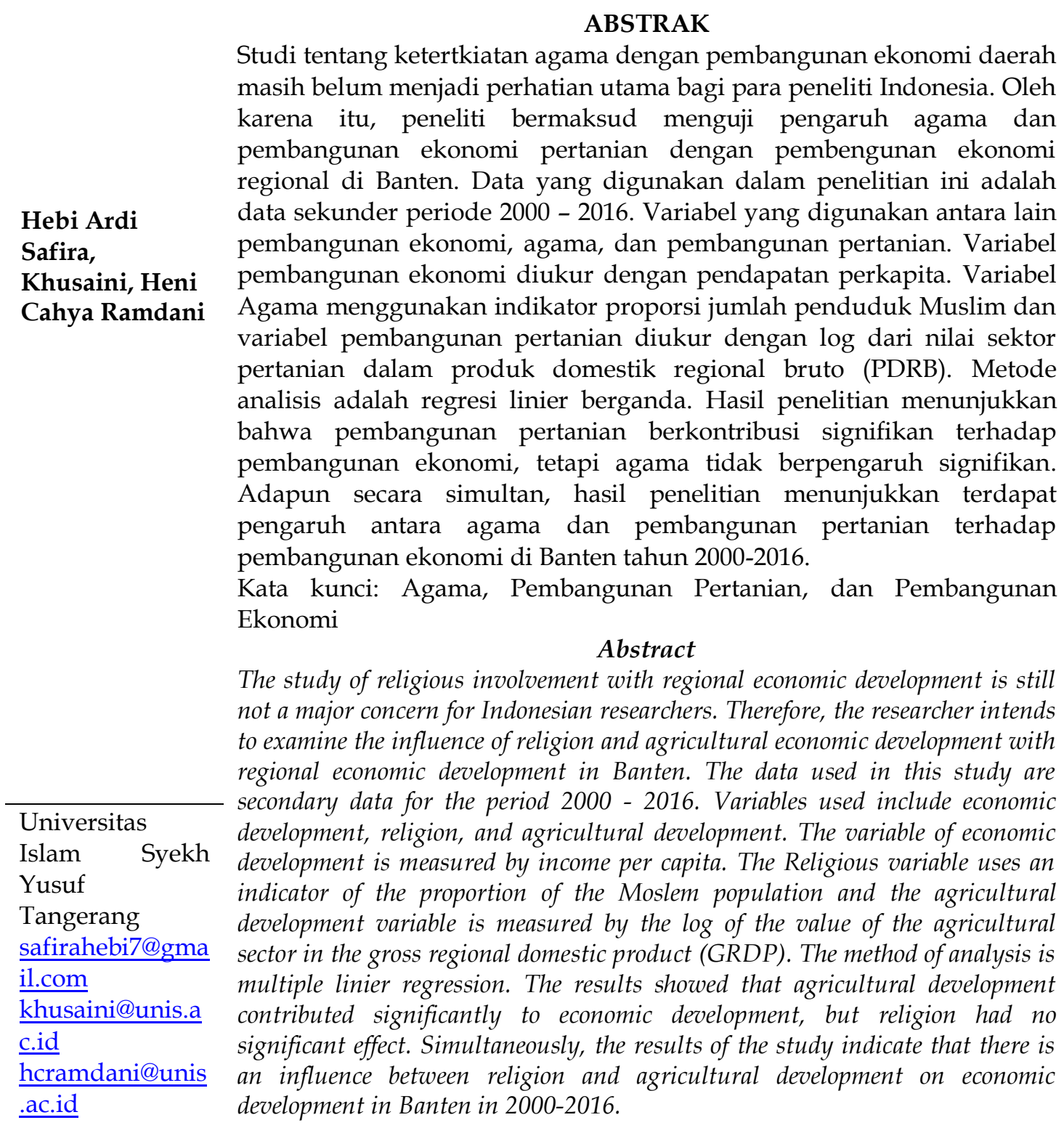

Keywords: Religion, Agricultural Development, and Economic Development

\section{A. PENDAHULUAN}

Pembangunan menjadi proses pelaksanaan kegiatan yang wajib dan penting dilakukan oleh tiap-tiap daerah, karena kemajuan IPTEK (Ilmu Pengetahuan dan Teknologi) dalam globalisasi mempengaruhi seluruh aspek kehidupan manusia, untuk suatu perubahan.Dalam pembangunan yang dilakukan tidak selalu identik dengan dengan petumbuhan ekonomi, namun lebih ditekankan pada peningkatan 


\section{PELITA}

kualitas dan kesejahteraan masyarakatnya(Khusaini, 2013). Terdapat beberapa faktor yang memberikan kontribusi pada keberhasilan pembangunan ekonomi, seperti yang dikemukakan olehMaridal (2013)yakni faktor lokasi geografis, sejarah, modal manusia, sistem politik dan kebijakan ekonomi.

Keberhasilan pembangunan ekonomi suatu daerah, salah satunya diukur dengan adanya peningkatah kesejahteraan masyarakat.Menurut Suparmoko (1992)menyatakan bahwa "Pembangunan ekonomi adalah upaya untuk meningkatkan taraf hidup bangsayang diukur dengan tinggi rendahnya pendapatan riil per kapita daerah/nasional".

Di satu daerah, terjadinya peningkatan pertumbuhan ekonomi daerah, distribusi hasil pembangunan, tercapainya stabilitas daerah merupakan sasaran akhir dari pembangunan ekonomi daerah.Jadi pembangunan ekonomi daerah merupakan proses pengelolaan sumber- sumber daya daerah oleh pemerintah daerah dan masyarakat, dengan sektor swasta untuk merangsang perkembangan pertumbuhan ekonomi.Menurut data BPS Provinsi tahun 2000-2016, laju perekonomian Banten fluktuatif dan memiliki kecenderungan menurun. Masih terdapat sejumlah permasalahan seperti angka kemiskinan dan masalah pembangunan ekonomi. Berikut adalah perbandingan laju pertumbuhan PDB/PDRB di Provinsi Banten dan Nasional periode tahun 2000-2016 dapat ditunjukan dengan diagram 1.

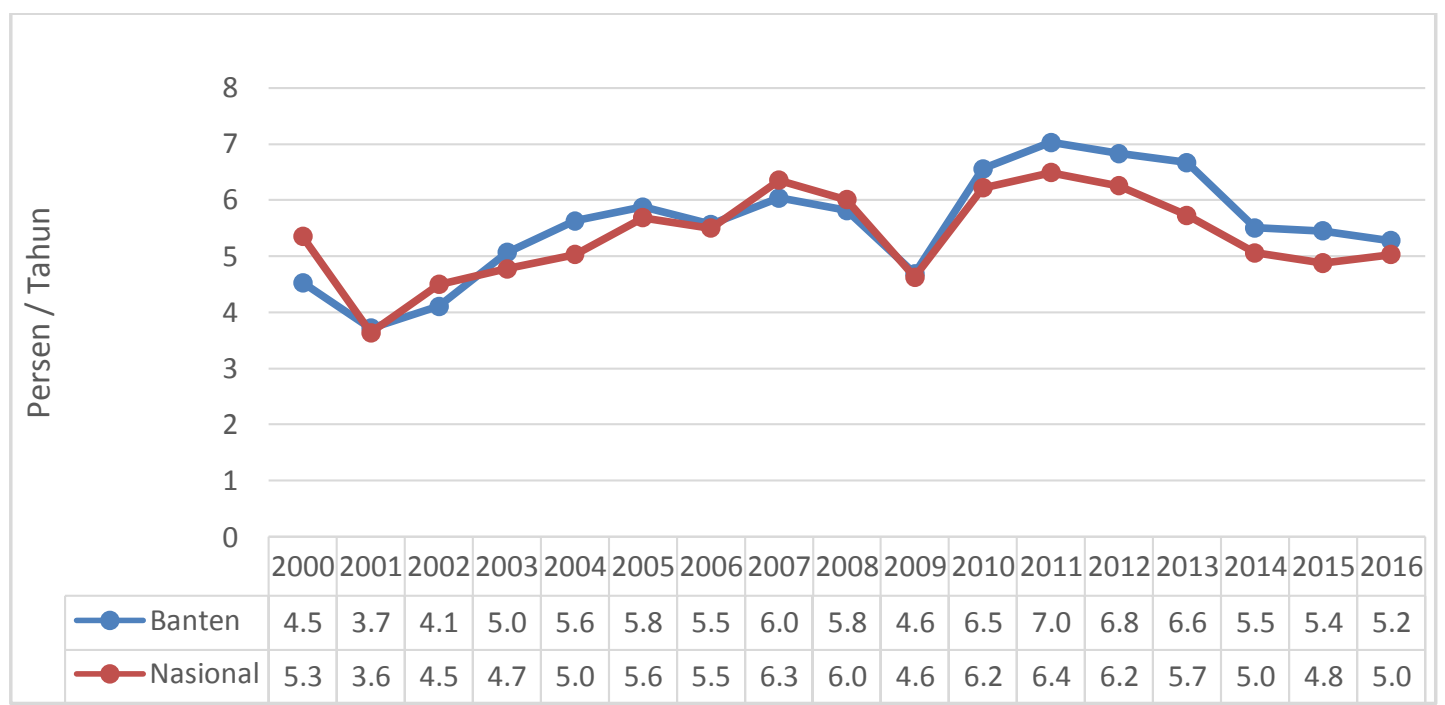

Sumber : BPS Provinsi Banten dan BPS Nasional

Diagram 1 Perbandingan PDB/PDRB Provinsi Banten dan Nasional tahun 2000-

2016

Berdasarkan diagram 1 menggambarkan bahwa telah terjadi penurunan pertumbuhan ekonomi yang cukup signifikan pada 2009. Penurunan tersebut 


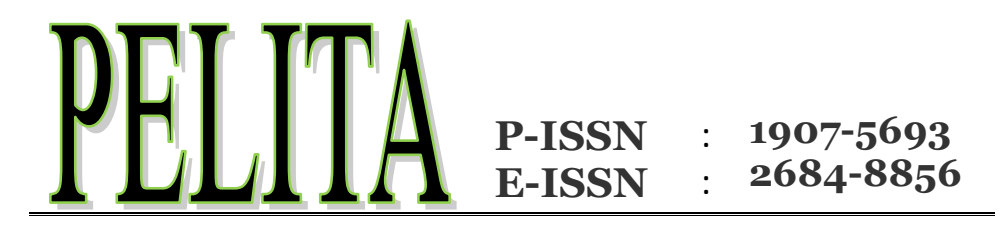

disebabkan oleh melambatnya pertumbuhan ekonomi global, akibatnya permintaan ekspor dari Banten juga mengalami penurunan. Di samping itu, penurunan tersebut juga diguga oleh partiapasi masyarakat yang beragama Islam dalam aktivitas ekonomi belum optimal.

Menurut Busler (2011)menyatakan bahwa budaya (sebagi ukuran agama) memainkan peran penting dalam pertukaran, tabungan, dan investasi, yang merupakan dasar untuk pembangunan ekonomi. Bahkan, Pratikto (2012) berpendapat bahwa adanya pengaruh budaya terhadap kinerja pembangunan perekonomian masih menjadi perhatian para ahli. Para ahli ekonomi menggunakan penjelasan budaya yang didalamnya terdapat agama untuk mengamati fenomena ekonomi.

Weber dalam Shi, Huang, Ye, \& Yu (2014) berpendapat bahwa Agama merupakan salah satu dimensi penting dari budaya.Agama merupakan implementasi dari karakteristik kehidupan sosial manusia yang universal. Istilah ini memiliki makna bahwa semua manusia sebagai anggota masyarakat memiliki cara berpikir dan pola perilaku yang mendasarkan pada tuntutan kepercayaan dan keyaknian yang dianutnya.

Abdullah(2002)berpendapat bahwa agama berfungsi sebagai motivator dalam proses perubahan pandangan hidup yakni kehidupan organisasi sosial ekonomi.Sementara itu, menurut Altman (2001) hal yang terpenting dalam pembangunan ekonomi yaitu penerapan norma- norma budaya dan adat istiadat yang paling bijak untuk memaksimalkan produktivitas dan kesejahteraan, karena pengaruh keuangan jauh tak terelakkan.

Seperti halnya Indonesia, yaitu negara yang memiliki kekayaan yang beragam yang mencakup berbagai kelompok etnis dan agama.Begitupun dengan Provinsi Banten yang memiliki keanekaragaman budaya dan agama, yang tidak terpisah dari unsur kegiatan ekonomi daerahnya. Berikut perbandingan kependudukan pemeluk agama di Provinsi Banten dan Nasional sensus tahun 2010 dapat dilihat pada diagram 2. 


\section{PELITA}

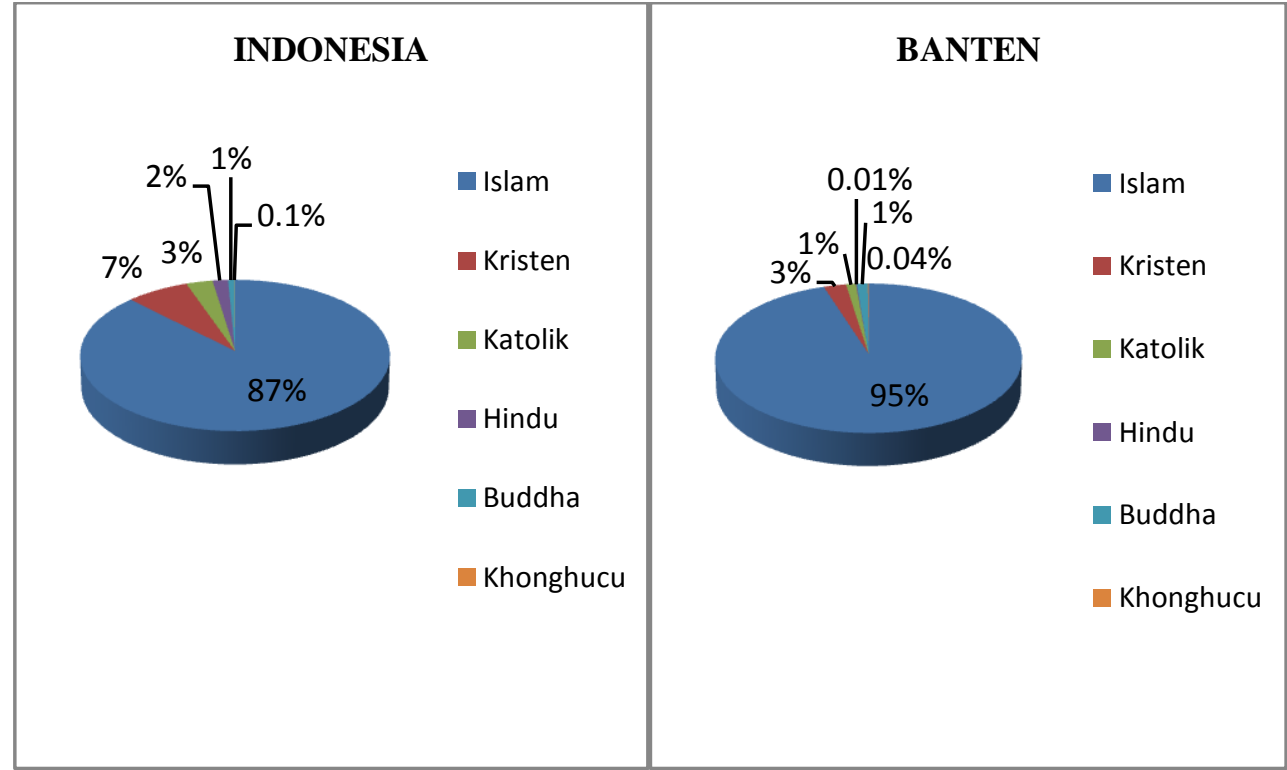

Sumber : BPS Provinsi Banten dan BPS Nasional 2018.

Diagram 2 Perbandingan Pemeluk Agama di Provinsi Banten dan Nasional Menurut Data Sensus 2010

Berdasarkan diagram 2 menunjukkan bahwa di Negara Indonesia dan Banten memiliki persamaan yaitu mayoritas penduduknya memeluk agama Islam. Berdasarkan survey nasional, Pemeluk agama Islam di Indonesia menempati populasi terbanyak sebesar $87 \%$ dari keseluruhan jumlah penduduk, dan Banten dengan populasi penduduk muslimnya sebesar 95\%. Negara Indonesia adalah Negara dengan penduduk muslim terbanyak didunia. Sama halnya di Provinsi Banten bahwa mayoritas penduduknya memeluk agama Islam, sehingga dapat dinyatakan bahwa hampir sebagian penduduk di Indonesia dan Banten memeluk agama Islam. Disamping itu, Banten juga memiliki kebudayaan dan adat istiadat yang masih terjaga dan sebagian besar masyarakatnya memeluk Islam dengan semangat religius yang tinggi. Total penduduk Banten pada tahun 2016 sebanyak \pm 12.203 .148 jiwa dengan total luas daerahnya $9.160 \mathrm{~km}^{2}$ (BPS, 2018).

Studi empiris sebelumnya yang memfokuskan keterkaitan antara agama dengan ekonomi diantaranya (Autiero \& Vinci, 2016; Belloumi, 2014; Noland, 2005). Wilayah kajian meliputi lintas negara dan negara maju dan dalam lingkup studi ekonomi makro. Terdapat studi juga pada tataran ekonomi mikro diantaranya(Nurrachmi, 2018; Tu, Bulte, \& Tan, 2011). Hasil studi mereka dapat disimpulkan bahwa terdapat hubungan timbal balik antara pembangunan dan institusi. Institusi yang dimaksud adalah lembaga informal seperti agama. Mereka mampu membuktikan bahwa agama menjadi faktor pendorong penting bagi bagi pembangunan ekonomi.

Distorsi peneragaman agama sangat penting, agar terhidar dari polarisasi. 


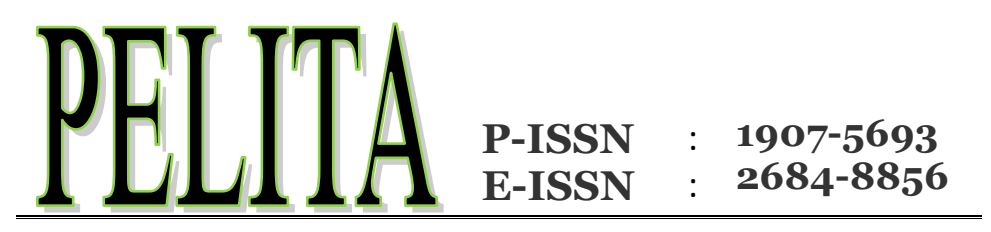

Karena adanya polarisasi agama berkorelasi negatif signfikan dalam peningkatan pertumbuhan ekonomi. Pengaruh polarisasi agama melalui pengeluaran pemerintah, adanya perang atau konflik sipil, dan investasi (Montalvo \& ReynalQuerol, 2003).

Jadi dapat dinyatakan bahwa semakin tinggi jumlah pemeluk agama dan menjalankan keyakinananya, maka akan berkontribusi dalam mewujudkan keberhasilan pembangunan ekonomi. Karena orang beragama tidak cukup dengan simbul agamanya, namun yang paling penting adalah sikap dan perilaku individu dalam menjalankan perintah agama dengan melakukan aktivitas ekonomi secara jujur, tanggung jawab, dan sebagainya. Karena memegang teguh agama merupakan subjek yang memengaruhi sikap dan aktivitas ekonomi individu, kelompok, dan masyarakat (Nurrachmi, 2018).

Daterminan lain yang mempengaruhi pembangunan ekonomi adalah pembangunan bidang pertanian. Banten, sebagai salah satu daerah yang sektor pertaniannya berkontribusi signfikan terhadap produk domestik regional bruto (PDRB). Disamping itu, sektor pertanian juga berkontribusi dalam menyediakan input sektor lainnya. Demikian demikian pembangunan pertanian berpengaruh signfikan terhadap pertumbuhan ekonomi dalam satu wilayah (Widyawati, 2017).

Hasil studi empiris Morkūnas, Volkov, \& Pazienza(2018) menjukkan bahwa telah peningkatan kontribusi nilai ketahanan ekonomi sektor pertanian terhadap perekonomian Uni Eropa Lithuania hingga tahun 2015, namun setelahnya terjadi penurunan ketahanan ekonomi sektor pertanian Lituania.Sedangkan (Anderson, 2009) menyimpulkan bahwa sektor pertanian dapat meningkatkan pendapatan perkapita.

Pendekatan berbeda dilakukan oleh Sari(2018) yang menguji kontribusi sub sektor pertnaian terhadap PDRB dengan pendekatan Location Quotient (LQ), Dynamic Location Quotient (DLQ) dan Shift- Share. Hasil penelitian menunjukkan bahwa subsektor pertanian menjadi sektor unggulan di Kabupaten Kaur. Peneliti lain sebelumnya menguji korelasi antara pembangunan pertanian dengan pembangunan ekonomi yang dikur dengan kemiskinan dan pengangguran. Hasil penelitian menujukkan bahwa sektor pertanian tidak berkontribusi pada penurunan kemiskinan, tetapi mampu mengurangi pengangguran di Indonesia(Mustika, 2018).

Salah satu cara meningkatkan kesejahteraan masyarakat adalah mengelola sektor pertanian dengan melakukan inovasi dan peningkatan keterampilan para petani, sehingga dapat meningkatkan produktivitas hasil pertanian. Mengiangat saat ini telah banyak alih fungsi lahan pertanian menjadi lahan hunian dan kawasan perdagangan. Alih fungsi lahan tentu berdampak pada penurunan hasil pertanian, yang pada akhirnya menurunkan kesejahteraan petani.Seperti dikatakan oleh 


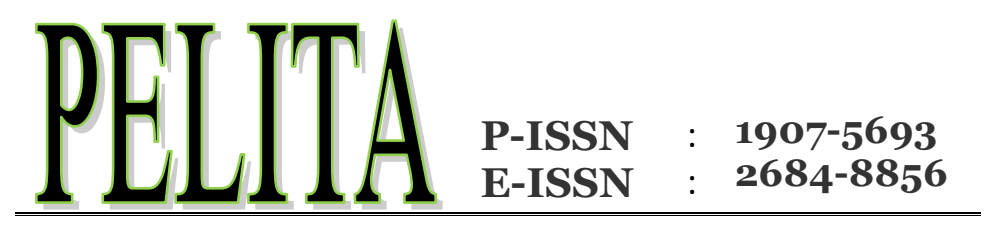

Todaro (1978) dalam (Prayitno \& Santosa 1980)bahwa syarat keberhasilan pembangunan nasional adalah pembangunan pertanian yang berhasil.

Penelitian ini dilakukan karena adanya kesenjangan pengukuran variabel agama dan budaya. Disamping itu, terdapat kesenjangan peenelitian tentang hubungan antara pembangunan pertanian dengan pembangunan ekonomi. Oleh karena itu, dalam penelitian ini dapat dirumuskan pertanyaan penelitian dalam artikel sebagai berikut:1)Apakah terdapat pengaruh yang signfikan Agama terhadap pembangunan ekonomi regional di Banten periode 2000 -2016?; dan2) Apakah terdapat pengaruh yang signfikan pembangunan pertanian terhadap pembangunan ekonomi regional di Banten periode 2000 -2016?Apakah secara simultan terdapat pengaruh yang signfikan agama dan pembangunan pertanian terhadap pembangunan ekonomi regional di Banten periode 2000 -2016?

\section{B. METODE}

Pengujian pengaruh agama dan pembangunan pertanian terhadap pembangunan ekonomi baik secara parsial maupun simultan digunakan metode deskriptif kuantitatif, yakni metode regresi linier berganda. Sebelum peneliti melakukan analisis model, peneliti melakukan beberapa pengujian statistik yang relevan, disntaranya uji normalitas residual, uji multikolinieritas, uji heteroskedastisitas, dan uji otokorelasi. Software statistik untuk pengolahan data adalah SPSS vesi 22.

Data yang digunakan adalah runtut waktu, yakni periode 2000 - 2016. Sumber data sekunder dariBPS Provinsi Banten, Bappeda dan instansi terkait lainnya. Variabel pembangnuan ekonomi diukur dengan PDRB perkapita, agama diukur dengan proporsi jumlah penduduk yang beragama Islam, dan pembangunan pertanian diukur dengan logaritma dari nilai barang dan jasa sektor pertanian.

Metode analisis data mengadaptasi dari model yang digunakan olehShi et al. (2014) dan dapat ditulis sebagai berikut:

$$
Y=\alpha_{0}+\alpha_{1} X_{1}+\alpha_{2} X_{2}+\varepsilon
$$

dimana $Y$ adalah pembangunan ekonomi, $X_{1}$ yaitu agama dan $X_{2}$ adalah pembangunan pertanian, $\alpha_{0}=$ konstanta, $\alpha_{i}=$ koefisien arah regresi, $\varepsilon=$ kesalahan pendugaan, dan $i=1,2$.

\section{HASIL PENELITIAN}

Deskripsi yaitu upaya yang dilakukan agar dapat memberikan suatu gambaran terhadap variabel-variabel yang digunakan dalam penelitian secara jelas dan tepat.Deskripsi statistik adalah gambaran data secara umum terkait statistik dasar yaitu mean, std.deviation, minimum, maximum, dan jumlah observasi. 


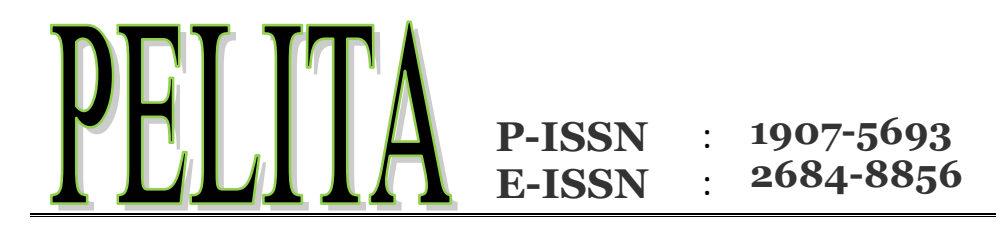

Tabel 1 Deskripsi Statistik

\begin{tabular}{lcrrrr}
\hline \multicolumn{1}{c}{ Variabel } & N & \multicolumn{1}{c}{ Min } & \multicolumn{1}{c}{ Max } & \multicolumn{1}{c}{ Mean } & Std. Deviasi \\
\hline Agama & 17 & 1,9106 & 1,9756 & 1,9755 & 0,0177 \\
Pembangunan Pertanian & 17 & 12,2473 & 13,0084 & 12,6193 & 0,2723 \\
Pembangunan Ekonomi & 17 & 3,3101 & 4,5019 & 3,8286 & 0,4021 \\
\hline
\end{tabular}

Sumber: Hasil Penelitian (datadiolah), 2018

Tabel 1 menunjukkan bahwa nilai maksimum, minimum, mean, dan standar deviasivariabel agama $\left(X_{1}\right)$ adalah masing-masing sebesar 1,$9756 ; 1,9106 ; 1,9755$; dan 0,0177. Sedangkan hasil perhitungan deskripsi statistik variabel pembangunan pertanian $\left(\mathrm{X}_{2}\right)$ maksimum, minimum, mean, dan standar deviasiadalah masingmasing sebesar 13,$0084 ; 12,2473 ; 12,6193$; dan 0,2723. Adapun variabel independen pembangunan ekonomi $(Y)$ meperoleh maksimum, minimum, mean, dan standar deviasiadalah masing-masing sebesar 4,5019; 3,3101; 3,8286; dan 0,4021.

Sebelum peneliti melakukan analisis model regresi linier berganda, maka pengujian persyaratan analisis harus dilakukan terlebih dahulu agar model analisis yang dihasilkan efisien dan tidak bias. Hasil pengujian normalitas residual data dengan metode Lilifors menunjukkan bahwa nilai signfikanasi sebesar 0,06 > 0,05. Hasil ini dapat disimpulkan bahwa data yang digunakan dalam penelitian ini adalah bersiditribusi normal. Sedangkan uji multikolineritas dengan menggunakan kriteria nilai tolerance $>0,1$ dan variance inflation vector $(\mathrm{VIF})<10$. Hasil uji multokolinieritas adalah nilai tolerance variabel agama $\left(X_{1}\right)$ dan pembangunan pertanian $\left(X_{2}\right)$ adalah sebesar 0,944 $>0,1$ dan nilai VIF adalah 1,059 < 10, sehingga dapat disimpulkan bahwa model telah terbebas dari masalah multikolinieritas.

Dalam model regresi linier berganda juga harus memenuhiasumsi homoskedastis. Untuk menguji heteroskedasitas dalam model ini digunakan uji Sparman's rho. Hasil pengujian menunjukkan bahwa nilai signifikansi korelasi Sperman's rho variabel agama sebesar 0,743 > 0,05 dan variabel pembangunan pertanian sebesar 0,667 >0,05 sehingga dapat disimpulkan bahwa model penelitian telah terbebas dari masalah heteroskedastisitas. Pengujian asumsi terakhir adalah uji otokorelsi dengan uji Durbin-Watson. Adapun hasil pengujian ini diperoleh nilai statistik Durbin-Watson sebesar adalah 1,558 sehingga kriteria diperoleh 4 - DW > $\mathrm{DU}=4-1,558>1,5361=2,442$ dan $\mathrm{DW}>\mathrm{DU}=1,558>1,5361$. Hasil ini dapat disimpulkan bahwa model penelitian telah terbebas dari masalah otokorelasi baik positif maupun negatif.

Hasil estimasi regresi linier berganda dan hasil pengujian hipotesis penelitian secara ringkas dapat dilihat pada tabel 2 berikut: 


\section{PELITA}

Tabel 2 Hasil Estimasi Regresi dengan Variabel Dependen:

Pembangunan Ekonomi Regional

\begin{tabular}{lccc}
\hline \multicolumn{1}{c}{ Variabel } & Koefisien & Standar Error & Signifikansi \\
\hline Agama $\left(\mathrm{X}_{1}\right)$ & $-2,525$ & 2,166 & 0,263 \\
Pembangunan Pertanian $\left(\mathrm{X}_{2}\right)$ & 1,338 & 0,140 & 0,000 \\
\hline Konstanta & $-8,120$ & 4,957 & 0,124 \\
\hline $\mathrm{R}^{2}$ & 0,880 & & \\
Obs & 17 & & \\
F-stat & 51,501 & & \\
Prob (F-stat) & 0,000 & & \\
Durbin-Watson & 1,558 & & \\
\hline
\end{tabular}

Sumber: Hasil pengolahan data (2018), SPSS 22

Tabel 2 menjelaskan bahwa nilai koefisien variabel agama $\left(X_{1}\right)$ adalah sebesar $-2,525$ dan nilai signifikansi sebesar 0,236. Hasil ini dapat dinyatakan bahwa terdapat pengaruh negatif agama terhadap pembangunan ekonomi regional di Banten, dengan asumsi ceteris paribus. Artinya jika tedapat peningkatan jumlah penduduk muslim sebesar 1\%, maka pendapatan per kapita akan menurun 25,25\%, atau sebaliknya. Namun hasil ini secara statistik tidak signifikan karena nilai signifikansinya 0,236 > 0,05 sehingga dapat disimpulkan bahwa hiptotesis yang telah ditetapkan adalah tidak terbukti.

Sedangkan hasil estimasi regresi linier berganda memperoleh nilai koefisien variabel pembangunan pertanian $\left(X_{2}\right)$ variabel sebesar 1,338 dan nilai signifikasi sebesar 0,000. Hasil ini dapat dinyatakan bahwa terdapat pengaruh positif pembangunan $\left(X_{2}\right)$ terhadap pembangunan ekonomi regional di Banten, dengan asumsi ceteris paribus. Artinya jika tedapat peningkatan hasil pertanian sebesar 1\%, maka pendapatan per kapita akan meningkat sebesar 13,38\%, atau sebaliknya. Hasil ini secara statistik signifikan karena nilai signifikansinya $0,000<0,05$ sehingga dapat disimpulkan bahwa hiptotesis yang menyatakan terdapat pengaruh positif dan signifikan pembangunan pertanian terhadap pembangunan ekonomi regional di Banten adalah terbukti.

Berdasarkan tabel 2 di atas juga dapat diketahui bahwa nilai F-stat sebesar 51,501 dan nilai signifikansi sebesar 0,000. Hasil ini dapat dinyatakan bahwa secara simultan variabel agama dan pembangunan pertanian berpengaruh signfikan terhadap pembangunan ekonomi regional di Banten dengan tingkat signifikansi sebesar 1\%. Sedangkan kontribusi kedua variabel tersebut ditunjukkan oleh nilai R2 sebesar 0,880 artinya pembangunan ekonomi regional di Banten ditentukan oleh variabel agama dan pembangunan pertanian sebesar $88 \%$, sedangkan sisanya 


\section{PELITA}

sebesar $12 \%$ ditentukan oleh faktor atau variabel yang lain yang tidak terdapat dalam model.

\section{PEMBAHASAN}

Keberadaan penduduk muslim di Banten seharusnya dapat berkontribusi dalam meningkatkan kesejahteraan masyarakat di Banten. Mengingat jumlah penduduk muslim di Banten berdasarkan sensus penduduk Banten 2010 sebanyak 94,67\% merupakan jumlah yang sangat besar. Namun dalam penelitian ini jumlah penduduk muslim yang besar belum mampu berkontribusi dalam pembangunan ekonomi selama periode penelitian. Peneliti tidak membuktikan hipotesis penelitian yang telah dirumuskan sebelumnya. Kurangnya kontribusi penduduk muslim di Banten ada kemungkinan belum adanya keterlibatan secara signifikan dari individu, lembaga-lembaga sosial kegamaan belum dipahami sebagai perulaku yang memiliki peran. Seperti dinyatakan oleh (Nurrachmi, 2018) bahwa "agama adalah aspek yang membentuk nilai manusia yang akan mempengaruhi bagaimana individu bertindak dalam masyarakat", termasuk tindakan dalam kegiatan ekonomi.

Temuan penelitan ini sejalan dengan dengan penelitian yang menyatakan bahwa agama tidak berpengaruh signifikan terhadap pembangunan ekonomi(Montalvo \& Reynal-Querol, 2003). Namun, temuan penelitian ini berbeda dengan yang menyimpulkan terdapat hubungan positif antara intensitas kepercayaan agama ('output' utama dari proses produksi religius) dan pendapatan kepercayaan tentang kehidupan setelah kematian mempengaruhi keputusan produksi dan tabungan hari ini (Wang \& Lin, 2014).Hasil studi lain dilakukan oleh(Autiero \& Vinci, 2016; Blum \& Dudley, 2001; Dudley, 2014; Noland, 2005; Shi et al., 2014) juga menemukan bahwa agama berpengaruh secara signifikan dan positif terhadap pembangunan ekonomi.

Peneliti lain mengukur kepercayaan terhadap sistem yang berlaku (agama) dengan budaya. Hasil penelitian menujukkan bahwa budaya ditemukan mempengaruhi kinerja ekonomi melalui dua saluran; sifat-sifat budaya yang merangsang motivasi individu, dan sifat-sifat yang mengembangkan modal sosial dalam populasi. Budaya didefinisikan sebagai kepercayaan masyarakat dan sistem nilai dan dioperasionalkan(Maridal, 2013). Namun peneliti lain memasukkan budaya model perilaku pertumbuhan dan perkembangan ekonomi, hasilnya ajaran budaya di masyarakat tidak mendorong pertumbuhan (Altman, 2001).

Pendekatan penelitian kualitatif Perspektif agama dari ekonomi mikro melihat bahwa agama dapat diekspresikan sebagai barang ekonomi yang harus bersaing dengan barang lain. Selain itu merupakan bagian dari pengembangan perilaku manusia melalui pengalaman religius dengan mengetahui tentang spiritualitas manusia dan dilema kematian manusia. Agama dan ekonomi dalam perspektif 


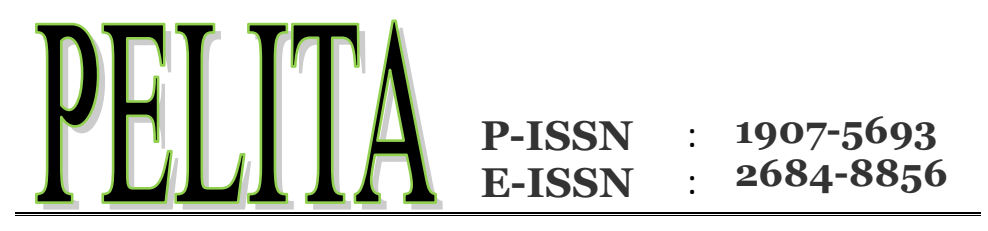

Islam adalah elemen timbal balik yang dapat meningkatkan perilaku manusia menjadi individu yang lebih baik menurut ajaran yang ada Al-Quran dan Sunnah(Nurrachmi, 2018). Oleh karena itu, penting bagi pemeluk agama Islam ampu mengimplementasikan nilai-nilai dan sikap yang luhur, diantaranya kejujuran, etis kerja, dan keyakinan. Nilai-nilai tersebut dimasukkan dalam keputusan-keputusan ekonomi dan tindakan dalam melakukan aktivitas ekonomi.

Pembangunan pertanian merupakan salah satu indikator penting yang memberi kontribusi terhadap pembangunan ekonomi regional. Pembangunan pertanian di Indonesia terus mengalami penurunan produktivitas. Hal ini ditunjukkan oleh kontribusi sektor pertanian terhadap pertumbuhan ekonomi. Menurunnya kontribusi pertanian disebabkan oleh meningkatnya alih fungsi lahan (khususnya lahan produktif) dan meningkatnya jumlah penduduk. Alih fungsi lahan tidak diimbangi dengan pembukaan lahan baru dan mengadaptasi teknologi pertanian. Hasil penelitian di Banten, membuktikan bahwa selama periode penelitian, pembangunan pertanian terbukti berkontribusi signfikan terhadap pembangunan ekonomi wilayah (daerah). Dengan asumsi ceteris paribus, semakin tinggi produktivitas pertanian, maka akan semakin meningkatkan kesejahteraan petani karena pendapatan perkapita mengalami peningkatan.

Hasil penelitian ini bersesuaian dengan penelitian sama dilakukan oleh (Alene \& Coulibaly, 2009; Riyadi \& Andri, 2015; Vaulina \& Rahmi, 2013; Widyawati, 2017) yang menemukan bahwa pembangunan pertanian berpengaruh positif dan signifikan terhadap pembangunan ekonomi dan meningkatkan pertumbuhan produktivitas yang ditunjukan oleh kenaikan pendapatan perkapita.Nilai tambah nilai tambah pertanian memiliki hubungan jangka panjang dalam menaikkan pendapatan perkapita. Selain itu, perluasan sektor pertanian juga memiliki dampak signifikan terhadap ekonomi dalam jangka panjang dan memperbaiki kondisi kehidupan penduduk(Moussa, 2018), bahkan sektor pertanian menjadi sektor unggulan (Sari, 2018).

Meskipun berbagai studi empris tersebut telah menemukan bukti tentang pentingnya sektor pertanian dalam pertumbuhan ekonomi dan pengurangan kemiskinan, namun terdapat sebagian kecil temuan lain yang bertentangan tentang peran pertanian dalam pembangunan ekonomi.Matsuyama(1992), misalnya, menunjukkan bahwa dengan asumsi ekonomi terbuka, terdapat hubungan negatif antara produktivitas pertanian dan pertumbuhan ekonomi. Tiffin \& $\operatorname{Irz}(2006)$ menemukan dalam studi mereka tentang kausalitas antara nilai tambah pertanian dan pertumbuhan ekonomi bukti empiris dari keberadaan kausalitas di negaranegara berkembang, tetapi tetap tidak jelas di negara-negara maju.Hasil yang sama juga ditunjukkan Mustika(2018) yang menyimpulkan bahwa sektor pertanian tidak 


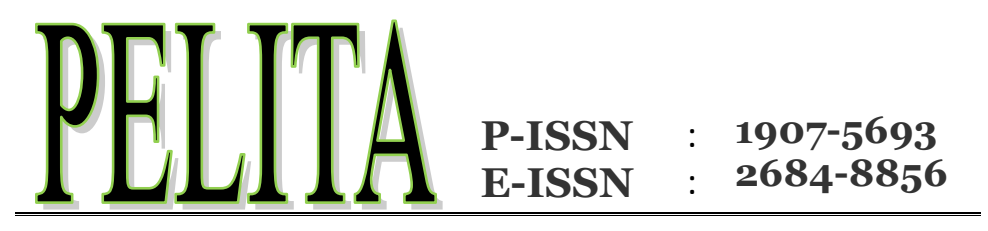

berkontribusi terhadap pembangunan ekonomi, yakni tidak menurunkan kemiskinan dan pengangguran.

Pemerintah daerah memiliki peran penting dalam upaya dan berinisiatif untuk mengoptimalkan produksi di sektor pertanian padi. Peran nyata yang dilakukan adalah dengan menjaga harga input dan output pertanian agar stabil. Hal ini ditujukan untuk mepertahankan produktivitas padi di Banten.Manfaat dari produktivitas hasil pertanian umumnya di wilayah pedesaan atau wilayah yang memiliki lahan pertanian produktif. Disamping itu, sektor pertanian dapat menyerap lebih banyak tenaga kerja dengan menyediakan bahan baku untuk sektor industri. Semua pelaku di sektor pertanian akan mendapat manfaat dari produksi dan dapat mengurangi pengangguran, kemiskinan, dan ketimpangan pendapatan masyarakat karena meningkatnya pendapatan perkapita.

\section{E. KESIMPULAN}

Hasil penelitian ini dapat disimpulkan bahwa agama belum memberikan kontribusi dalam pembangunan ekonomi ekonomi regional di Banten. Tingginya jumlah penduduk Muslim bukan menjadi jaminan bekontribusi optimal dalam meningkatkan kesejahteraan di Provinsi Banten. Sedangkan pembangunan pertanian, sebaliknya mempunyai kontribusi yang signfikan dalam mendorong keberhasilan pembangunan ekonomi di Provinsi Banten selama periode penelitian. Meningkatnya pembangunan pertanian mampu mendorong peningkatan kesejahteraan masyarakat.

Hasil penelitian ini merekomendasikan kepada Pemreintah Provinsi Banten agar miningkatkan pemahaman dan keterampilan petani untuk dapat melakukan inovasi dan penggunakan teknologi pertanian, eiring dengan penurunan lahan pertanian dan meningkatnya permintaan penduduk terhadap hasil pertanian. Disamping itu, pemerintah dapat menetapkan kebijakan perbaikan dan pengembangan inftrastruktur pertanian. Pemerintah daerah juga terus melakukan dan menjaga kestabilan harga-harga input pertanian seperti harga pupuk, bibit, harga sewa, harga obat-obatan yang mengnanggubtanaman pertanian. Yang tidak kalah pentingnya juga menjaga harga hasil pertanian untuk tetap stabil, agar kesejahteraan petani tidak mengalami penurunan.

Bagi peneliti selanjutnya disarankan memperluas lokasi penelitian dan memperbanyak periode penelitian. Variabel penting non ekonomi yang perlu digunakan adalah etnis dan tingkat pendidikan penduduk. Sedangkan model analisis yang dapat digunakan adalah model panel data baik model statis maupun model dinamis. Mengingat dalam penelitian ini terdapat keterbatasan pengukuran variabel agama dan jumlah series yang relatif kecil. 


\section{PELITA}

\section{F. REFERENSI}

Abdullah, I. (2002). Tantangan pembangunan Ekonomi Dan Transformasi Sosial: Suatu Pendekatan Budaya. Humaniora, 14(3), 260-270. https://doi.org/10.22146/jh.v14i3.762

Alene, A. D., \& Coulibaly, O. (2009). The impact of agricultural research on productivity and poverty in sub-Saharan Africa. Food Policy, 34(2), 198-209. https://doi.org/10.1016/j.foodpol.2008.10.014

Altman, M. (2001). Culture, human agency, and economic theory: culture as a determinant of material welfare. Journal of Socio-Economics, 30, 379-391.

Anderson, K. (2009). Distorted agricultural incentives and economic development: Asia's experience. World Economy, 32(3), 351-384. https://doi.org/10.1111/j.1467-9701.2009.01163.x

Autiero, G., \& Vinci, C. P. (2016). Religion, human capital and growth. International Journal of Social Economics, 43(1), 39-50. https://doi.org/10.1108/IJSE-06-20140108

Belloumi, M. (2014). The relationship between trade, FDI and economic growth in Tunisia: An application of the autoregressive distributed lag model. Economic Systems, 38(2), 269-287. https:/ / doi.org/10.1016/j.ecosys.2013.09.002

Blum, U., \& Dudley, L. (2001). Religion and economic growth: Was Weber right? Journal of Evolutionary Economics, 11(2), 207-230. https://doi.org/10.1007/PL00003862

BPS. (2018). Provinsi Banten Dalam Angka 2018. Banten: Badan Pusat Statistik.

Busler, M. (2011). World Journal of Entrepreneurship , Management and Sustainable Development Article information: https://doi.org/10.1108/03090560310495429

Dudley, U. (2014). Religion and Economic Growth: Was Weber Right? Journal of Evolutionary Economics, 11(2), 207-230. https://doi.org/10.1007/PL00003862

Khusaini, K. (2013). Analisis Pengeluaran Pendidikan dan Pertumbuhan Ekonomi Inklusif dan Berkelanjutan di Indonesia. Jurnal PELITA, II(XII), 1-35. Retrieved from http://journal.unis.ac.id/jurnal.php?detail=jurnal\&file=1. artikel pelita khusaini 2.pdf\&id=557\&cd=0b2173ff6ad6a6fb09c95f6d50001df6\&name=1. artikel pelita khusaini 2.pdf

Lanjut, P., \& Di. (2010). Kabupaten Kulon Progo, 1(2), 78-85.

Maridal, J. H. (2013). Cultural impact on national economic growth. Journal of SocioEconomics, 47, 136-146. https:// doi.org/10.1016/j.socec.2012.08.002

Matsuyama, K. (1992). Agricultural productivity, comparative advantage, and economic growth. Journal of Economic Theory, 58(2), 317-334. https://doi.org/10.1016/0022-0531(92)90057-O

Montalvo, J. G., \& Reynal-Querol, M. (2003). Religious polarization and economic development. Economics Letters, 80(2), 201-210. https://doi.org/10.1016/S0165- 


\section{PELITA}

1765(03)00080-6

Morkūnas, M., Volkov, A., \& Pazienza, P. (2018). How resistant is the agricultural sector? Economic resilience exploited. Economics and Sociology, 11(3), 321-332. https://doi.org/10.14254/2071-789X.2018/11-3/19

Moussa, A. (2018). Does Agricultural Sector Contribute to the Economic Growth in Case of Republic of Benin? Journal of Social Economics Research, 5(2), 85-93. https://doi.org/10.18488/journal.35.2018.52.85.93

Mustika, C. E. (2018). Dampak output GDP sektor pertanian terhadap masalah pembangunan ekonomi di Indonesia ( kemiskinan dan pengangguran ). Jurnal Paradigma Ekonomika, 13(1), 22-28.

Noland, M. (2005). Religion and economic performance. World Development, 33(8), 1215-1232. https://doi.org/10.1016/j.worlddev.2005.03.006

Nurrachmi, R. (2018). Religion and Economic Performance (MPRA Paper No. 85582). Munich. Retrieved from https://mpra.ub.uni-muenchen.de/85582/

Pratikto, A. (2012). Pengaruh Budaya Terhadap Kinerja Perekonomian. Buletin Studi Ekonomi, 17(2), 98-115.

Prayitno, H., \& Santosa, B. (1980). Ekonomi Pembangunan - Hadi Prayitno.pdf. Jakarta: Ghalia Indonesia.

Riyadi, A., \& Andri, K. B. (2015). Analisis kinerja sektor pertanian dalam pembangunan wilayah di Provinsi Sulawesi Barat. AGRISE, XV(2), 94-100. Retrieved from https://agrise.ub.ac.id/index.php/agrise/article/download/166/181

Sari, S. R. (2018). Kontribusi Sektor Pertanian Dalam Struktur Ekonomi Di Kabupaten Kaur Provinsi Bengkulu. Jurnal AGRISEP: Kajian Masalah Sosial Ekonomi Pertanian Dan Agribisnis, 17(2), 175-186. https://doi.org/10.31186/jagrisep.17.2.175-186

Shi, S., Huang, K., Ye, D., \& Yu, L. (2014). Culture and regional economic development: Evidence from China. Papers in Regional Science, 93(2), 281-299. https://doi.org/10.1111/pirs.12114

Suparmoko, I. (1992). Ekonomi Pembangunan - Irawan.pdf (kelima). Yogyakarta: BPFE Yogyakarta.

Tiffin, R., \& Irz, X. (2006). Is agriculture the engine of growth? Agricultural Economics, 35(1), 79-89. https:// doi.org/10.1111/j.1574-0862.2006.00141.x

Tu, Q., Bulte, E., \& Tan, S. (2011). Religiosity and economic performance: Microeconometric evidence from Tibetan area. China Economic Review, 22(1), 55-63. https:// doi.org/10.1016/j.chieco.2010.09.008

Vaulina, S., \& Rahmi, E. (2013). Peran Sektor Pertanian Dalam Perekonomian Kabupaten Indragiri Hilir Provinsi Riau. Jurnal Dinamika Pertanian, XXVIII(3), 245-254.

Wang, Q., \& Lin, X. (2014). Does religious beliefs affect economic growth? Evidence from provincial-level panel data in China. China Economic Review, 31, 277-287. 


\section{PELITA}

https://doi.org/10.1016/j.chieco.2014.10.006

Widyawati, R. F. (2017). Analisis Keterkaitan Sektor Pertanian Dan Pengaruhnya Terhadap Perekonomian Indonesia (Analisis Input Ouput). Jurnal Economia, 13(1), 14.https://doi.org/10.21831/economia.v13i1.11923 